\title{
0038 THE QUALITY IMPROVEMENT IN TRAUMA CARE SYSTEM; KHON KAEN HOSPITAL;THAILAND
}

N Tippayanate* Correspondence: Khon Kaen Hospital, Trauma and Critical Care Center,Khon Kaen Hospital, Sricharn Road, Muang district, Khon Kaen Province 40000, Thailand

\subsection{6/ip.2010.029215.38}

Background Khon Kaen Hospital is the second level of trauma excellence centre in Thailand. The numbers of injury were increasing year by year, therefore the continuing quality improvements in trauma care were needed (ie, trauma alert team, MM-death case conference, root cause analysis and trauma quality round).

Objectives To know the injury epidemiology and to monitor the quality of trauma care.

Methods To compare the injury and death rate related with mean Injury Severity Scale (ISS) before and after implementation. Injury Surveillance software was used with retrospective database of all injuries between 1 January 2008 and 30 June 2009, all analysed by descriptive statistics (ie, correlation, t test).

Results The number of injury was of 24417 cases (male 16 267: female 8150 ). The trend of injury rate was increasing at $2.4 \%$ rate, with a mean age of deaths decreasing from 35.7 to 33.4 years old, bearing male injury rate increasing from $66.6 \%$ to $68.3 \%$. It was found that the gender and age had an impact on the severity $(p=0.000)$ and the severity had a significant impact on mortality and survival rate $(\mathrm{p}=0.000)$. The admission numbers showed 7860 cases ( $32 \%$ ), the survival rate increased from $90.3 \%$ to $92.9 \%$, with an increasing mean of ISS from 6.8 to 7.3 , while the mortality decreased from $1.64 \%$ to $1.39 \%$ with stable mean ISS (27.4-27.6).

Conclusion These results could be used to confirm the quality of trauma care in hospital was improving and the quality improvement activities should be continued and disseminated. 